\title{
Cost effectiveness of combination therapy for hepatitis C: a decision analytic model
}

\author{
K Stein, W Rosenberg, J Wong
}

See end of article for authors' affiliations

Correspondence to:

Dr K Stein, Dean Clarke

House, Southernhay East,

Exeter EXI 1PQ, UK.

ken@kkcats.demon.co.uk

Accepted for publication 15 May 2001
Objective: To estimate the cost utility of treatment with combination therapy (ribavirin and interferon $\alpha)$ for hepatitis $C$ compared with no treatment or monotherapy (interferon $\alpha$ ) based on UK costs and clinical management.

Design: Decision analysis model using a Markov approach to simulate disease progression.

Setting: UK secondary care.

Participants: Hypothetical cohort of patients with hepatitis $C$.

Main outcome measures: Cost per quality adjusted life year (QALY) gained.

Results: Discounted cost per QALY for combination therapy over no treatment was $£ 3791$. Cost per QALY varied between $£ 1646$ and $£ 9170$ according to subgroup, with the lowest ratios being for genotype 2 or 3 , women, those aged less than 40 years, and those with moderate hepatitis. The discounted cost per QALY of the combination over monotherapy was $£ 3485$. Similar findings were shown for subgroups as for the comparison with no treatment. One way sensitivity analysis showed that while drug costs were more important in the analysis than assumptions about disease progression or costs of treating hepatitis $C$ disease, the results were robust to large changes in underlying assumptions.

Conclusions: Combination therapy for hepatitis $C$ is a cost effective treatment option and is superior to monotherapy. Considerable uncertainties remain over the appropriate management strategies in the populations excluded from randomised controlled trials and in whom treatment is currently being considered in the UK.
$\mathrm{H}$ epatitis C (HCV) is an important public health problem, characterised by prevalence, chronicity, and latency. Prevalence estimates vary with the population studied. ${ }^{1}$ Prevalence in blood donors may be as low as $0.04 \% .^{2}$ A UK community based survey showed seroprevalence of $0.7 \%$ in $1994^{3}$ and a more recent antenatal clinic based survey showed seroprevalence of $0.8 \% .{ }^{4}$ Rates among intravenous drug users may be at least $60 \% .^{5}$ Infection persists in the majority of infected cases ${ }^{6}$ with a clinical latency of decades before a wide range of hepatic manifestations of which the most important are cirrhosis and hepatocellular carcinoma. ${ }^{67}$ Approximately $30 \%$ of those with chronic infection develop cirrhosis within 20 years, ${ }^{8}$ and these are at risk of developing hepatocellular cancer at a rate of $3 \%$ per annum.

HCV accounts for $30 \%$ of liver transplants in the USA. ${ }^{9}$ Data on HCV related transplants have been collected centrally by the UK Transplant Support Services Authority (UKTSSA) since 1995. In the UK, the number of liver transplants increased from 315 to 632 between 1990 and 1998. HCV related cirrhosis has been recorded as the primary disease leading to transplantation in $11 \%$ of transplants since then, with a near doubling in the number of HCV related transplants from 44 to 79 between 1995 and 1998 (UKTSSA, personal communication, September 1999).

Recombinant interferon $\alpha$ (IFN- $\alpha$ ) therapy was licensed in the UK for the treatment of HCV infection in 1995. Sustained viral response, defined by viral clearance six months after the end of therapy, is observed in approximately 15\% of treated patients but not in untreated patients. Ribavirin was licensed in 1999 for use in combination with IFN- $\alpha$. Evidence from randomised controlled trials shows that combination therapy results in eradication of virus and normalisation of liver function in $40 \%$ of treated subjects, which is $25 \%$ more patients than with interferon monotherapy given for 48 weeks. ${ }^{10}{ }^{11}$ The higher response rates observed with combination therapy are accompanied by increased costs of treatment attributable to ribavirin. Commissioners of health care and clinicians have expressed considerable interest in the balance between cost and benefit of treatment.

Given the long clinical course of HCV infection, it is not feasible to use randomised controlled trials to investigate the extent to which these intermediate outcomes translate into improvements in survival or quality of life gains in the long run. Furthermore, it is not known whether the short term costs of treatment may be offset by savings on health care budgets, such as that saved by avoidance of liver transplantation. This prompted us to use a decision analysis model ${ }^{12}$ to investigate the value of combination therapy in UK practice. The National Institute for Clinical Excellence recently recommended that combination therapy should be offered to patients with moderate to severe HCV on the basis that it is clinically and cost effective (http://serverl.nice.org.uk/niceweb/Article.asp?a = 11676) .

We addressed the following questions:

(1) What is the cost utility of combination therapy for chronic HCV infection in UK patients compared with no treatment?

(2) What is the cost utility of combination therapy compared with interferon monotherapy in those with chronic HCV infection being treated in the UK?

(3) Is combination therapy more cost effective than no treatment or monotherapy in certain groups of patients with chronic HCV infection?

\section{METHODS}

General approach

We used a Markov model to simulate progression through the various states of ill health involved in progressive HCV disease,

Abbreviations: HCV, hepatitis C virus; QALY, quality adjusted life year; UKTSSA, UK Transplant Support Services Authority; HRG, Healthcare Resource Group; IFN- $\alpha$, interferon $\alpha$. 
including death (from hepatic and other causes), using DecisionMaker 7.07 (Pratt Medical Group, Boston, USA). In this approach a cohort of hypothetical patients move between specified health states on an annual basis according to probabilities for progression based on best available evidence. For each annual cycle, the model tracks how many patients are in each state so that, given estimates for the quality of life and resource use associated with the health states, the model yields an average lifetime cost utility for each strategy and allows estimation of the marginal cost per quality adjusted life year (QALY) gained. This approach to modelling HCV disease progression performs well when compared with existing cohort data. ${ }^{13-15}$ The model was originally developed by one of us (JW) to investigate aspects of management of HCV disease in a North American setting. In this study we adapted the model for the UK. The analysis is undertaken primarily from the perspective of UK commissioning authorities (primary care groups/trusts and district health authorities). Where possible, information is included that allows a wider societal perspective to be taken.

\section{Parameters used in the analysis Patient population}

At the start of the model, patients are in one of several states of compensated chronic HCV infection defined by sustained abnormal liver function and histological status. These states also summarise the populations studied in the two clinical trials of combination and monotherapy. ${ }^{10}{ }^{11}$ Three variables have been consistently identified as predicting improved sustained response to antiviral therapy ${ }^{16-22}$ and these are considered when calculating the cost effectiveness of targeted treatment strategies: histological type (mild hepatitis, moderate hepatitis, or cirrhosis); level of viraemia; and viral genotype ( 1 and 4 , or other).

Following the inclusion criteria of the clinical trials of interferon (alone or in combination), and current practice in the UK, the model does not consider treatment in patients with persistent chaotic intravenous drug use, excessive alcohol consumption, psychiatric disorders including depression, ischaemic heart disease, severe respiratory disease, or diabetic retinopathy.

\section{Natural history}

The model has been described in more detail previously. ${ }^{13}$ For progression of non-compensated disease, we used pooled estimates from three retrospective observational studies of non-A non-B hepatitis in which subsequent serology showed HCV as the causative agent, ${ }^{23-25}$ and a published cohort study of compensated cirrhosis. ${ }^{14}$ Prognosis following decompensation varies according to the predominant clinical feature at presentation-that is, ascites (diuretic sensitive or refractory), variceal haemorrhage, and hepatic encephalopathy. ${ }^{26-28}$ We assumed that recovery from decompensated to compensated states would only occur in the event of transplantation. Risk of development of hepatocellular carcinoma was estimated as $1-3 \%$ per year in patients with cirrhosis. ${ }^{142930}$ Probability of death from other causes was calculated from UK age specific tables.

\section{Transplantation}

It is difficult to estimate the transplantation rate in the UK population. In England and Wales in 1998, there were 632 liver transplantations (UKTSSA, personal communication, September 1999). This gives an overall population rate for transplantation of 12 per million, which is $80 \%$ of that in the USA where the annual probability for transplantation in the eligible HCV infected population is $3.1 \%$. We therefore estimated the annual UK transplantation probability as $2.5 \%$ ( $80 \%$ of $3.1 \%$ ).

\section{Antiviral treatment}

Response rates were based on the results of combined US and international trials of interferon and ribavirin combination therapy. ${ }^{10}{ }^{11}$ Individual patient data were combined to examine response rates in several subgroups.

- Genotype 1 versus genotype 2 or 3; $50 \%$ of UK HCV sufferers have genotype 1 .

-Viral load, defined as (a) $>2$ million copies/ml or (b) $\leqslant 2$ million copies/ml.

- Sex.

- Histological grade: mild or moderate hepatitis.

-Age: 40 years and under; 41-50 years; and over 50 years of age.

As a bias against therapy, we assumed that a few treatment responders could experience ongoing progression after sustained viral clearance, ${ }^{31}$ despite the observation of regression of fibrosis following response to interferon monotherapy. ${ }^{32}$

Treatment duration was 24 weeks for genotype 2 or 3 , and 48 weeks otherwise. If the patient remained viral positive, we assumed monotherapy would be stopped at 12 weeks and combination therapy would be stopped at 24 weeks. Where response was shown at these points, it was assumed treatment would continue for 12 months except in the subgroup of genotype 2 or 3 where treatment would be limited to 24 weeks. We calculated average costs of treatment for the treated cohorts based on these stopping rules.

Drug costs were calculated on a per diem basis with prices taken from the British National Formulary. ${ }^{33}$ Drug dosage is related to weight. Based on the experience of the randomised controlled trials of combination therapy, dosage was as received in the combined trials. In a European population, this likely overestimates the dose because US patients were heavier.

\section{Resource use and valuation}

Resource use is based on typical UK management of HCV disease in each of the health states concerned (see table 1). Management patterns were determined using a questionnaire survey of nine UK liver units, including five transplant centres. Net ingredient costs for drug treatments are from the British National Formulary, March $1999 .{ }^{33}$ Cost of transplantation was estimated from the average contract price of liver transplantation in the UK for 1997/8. ${ }^{34}$ This includes costs for transplantation and follow up. Costs have been estimated for 1998/9 using, where appropriate, the Hospital and Community Health Services Index to adjust values. ${ }^{35}$

Cost estimates for procedures and diagnostic tests (at 1998 prices) were provided by the costings units at Ninewells Hospital, Dundee (Dr D Carson, personal communication, September 1999), from a small purposive sample of NHS trust financial managers surveyed in September 1999 (listed at the end of the paper) and by reference to published tariffs from hospitals in the South and West regions of the UK. ${ }^{36}$ Unit costs of items associated with drug treatment and outpatient management of HCV disease are shown in table 2. Costs of inpatient admissions for complications of chronic HCV infection were taken from NHS Healthcare Resource Group (HRG) reference costs. HRGs used in relation to health states involved are shown in table 3. HRGs include all hotel and treatment costs associated with admission, including drugs and investigations. However, as combination therapy was not a standard part of management at the time HRG costs were estimated by trusts, we have assumed that HRGs exclude this element.

\section{Utility of health states}

We used the utility values obtained by Wong et al from American hepatologists using the standard gamble and time trade off techniques in their study of pretreatment evaluation strategies in HCV disease ${ }^{31}$ to weight the time spent in each health state for quality of life (see table 4). These values were checked with UK hepatologists. 
Table 1 Assumptions regarding resource use in health states considered in the model and management on combination therapy

\begin{tabular}{|c|c|}
\hline Health state & Assumptions \\
\hline Mild hepatitis & Annual outpatient review with LFT, FBC, U\&E, clotting studies, urinalysis. Liver biopsy at initial staging only. \\
\hline Moderate hepatitis & Six monthly or annual review with LFT, FBC, U\&E, clotting studies, urinalysis. Liver biopsy at initial staging only. \\
\hline Compensated cirrhosis & $\begin{array}{l}\text { Three monthly outpatient review with LFT, FBC, U\&E, clotting studies, urinalysis. Liver biopsy at } 5 \text { year intervals } \\
\text { if not on treatment. Six monthly screening for hepatocellular carcinoma using AFP and ultrasound. }\end{array}$ \\
\hline \multirow[t]{2}{*}{ Decompensated cirrhosis } & $\begin{array}{l}\text { Six monthly screening for hepatocellular carcinoma using AFP and ultrasound. For specific health state we } \\
\text { assumed the following, based on US information, verified as being appropriate by UK hepatologists: }\end{array}$ \\
\hline & $\begin{array}{l}\text { - Ascites sensitive to diuretics: } 2.3 \text { admissions per year } \\
\text { - Variceal haemorrhage: } 2.3 \text { admissions in the first year and } 0.033 \text { thereafter } \\
\text { - Hepatic encephalopathy: } 2.3 \text { admissions in the first year and } 0.033 \text { thereafter }\end{array}$ \\
\hline Hepatocellular cancer & $\begin{array}{l}\text { We assumed there would be two admissions for palliative care in the year after diagnosis, based on the local } \\
\text { experience of one of us (WR). }\end{array}$ \\
\hline Post liver transplantation & $\begin{array}{l}\text { We assumed there would be } 2.4 \text { admissions in the first year after transplantation and thereafter } 0.7 \\
\text { admissions per year and an ongoing } 5 \% \text { annual probability of further transplantation, based on US practice } \\
\text { and supported by UK hepatological opinion }\end{array}$ \\
\hline Management on combination therapy & $\begin{array}{l}\text { We based management practice on reports from our survey of nine specialist hepatology centres and local } \\
\text { data from one of us (WR). Baseline tests: FBC, U\&E, clotting studies, LFT, HCG (females), urinalysis, AIS, USS, } \\
\text { TFT. Psychiatric assessment in } 2 \% \text { of cases, fundal photography in } 3.5 \% \text {, ultrasound scan in } 7.5 \% \text {, pulmonary } \\
\text { function tests in } 2 \% \text {. Thyroid function tests at initiation of therapy and then three monthly during treatment. Liver } \\
\text { biopsy following treatment in } 68 \%\end{array}$ \\
\hline
\end{tabular}

AFP, $\alpha$ fetoprotein; LFT, liver function tests; FBC, full blood count; U\&E, urea and electrolytes; HCG, human chorionic gonadotrophin; AIS, autoimmune screen; USS, ultrasound scan; TFT, thyroid function tests.

Table 2 Unit costs of items associated with drug treatment of HCV or outpatient management of hepatic complications

\begin{tabular}{|c|c|c|}
\hline Variable & Cost (£) & Source and notes \\
\hline Liver transplant & 46289 & National Specialist Commissioning Advisory Group \\
\hline $\begin{array}{l}\text { Routine pathology testing (LFT, } \\
\text { FBC, U\&E, clotting, urinalysis) }\end{array}$ & 25.09 & Ninewells Hospital costings unit \\
\hline Thyroid function test & 8.00 & Ninewells Hospital costings unit \\
\hline Serum HCG & 9.80 & Ninewells Hospital costings unit \\
\hline Liver ultrasound & 29.72 & Average of estimates from survey of small sample of NHS trusts undertaken for this study \\
\hline Chest $x$ ray & 13.86 & Average of estimates from survey of small sample of NHS trusts undertaken for this study \\
\hline Liver biopsy & 449.00 & ECR cost for investigation of HCV disease (Southampton University Hospitals Trust) \\
\hline Outpatient attendence & 81.00 & ECR cost of outpatient attendence for HCV disease (Southampton University Hospitals Trust) \\
\hline Psychiatric assessment & 97.57 & From 1998 national pay scales (assuming 50\% client contact time and one hour for assessment). \\
\hline \multicolumn{3}{|r|}{ 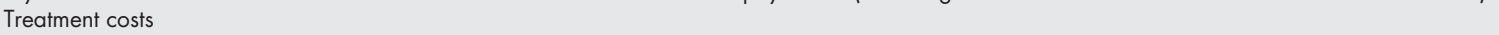 } \\
\hline IFN- $\alpha$ per mU & 5.40 & Schering Plough \\
\hline Ribavirin, per pill & 3.53 & \\
\hline Fundal photography & 20.00 & University of Bristol Hospitals Trust (the only trust in the survey able to make an estimate) \\
\hline Inpatient palliative care & 2544 & $\begin{array}{l}\text { ECR price for admission to palliative care (medium complexity case) at Southampton University } \\
\text { Hospitals Trust }\end{array}$ \\
\hline
\end{tabular}

\section{Sensitivity analysis}

We carried out one way sensitivity analyses to investigate the effect on the model of varying key cost and disease progression parameters by $50 \%$ upwards and downwards. Costs and benefits were discounted at $6 \%$.

\section{RESULTS}

\section{Main analysis}

The results of the main analysis are shown in table 5. Average cost of drug treatment per patient was $£ 2738$ for interferon monotherapy and $£ 7014$ for combination therapy.

\section{Subgroup analyses}

The results of the subgroup analyses are shown in table 6. We present only the results with benefits and costs discounted at $6 \%$. These therefore represent the highest estimates of cost effectiveness to current commissioners.

\section{Sensitivity analyses}

The results of sensitivity analyses are shown in table 7 . The conclusions of the main analysis are not markedly sensitive to variation in key parameters, although drug cost appears to be

Table 3 Healthcare resource groups (HRGs) used to estimate inpatient resource use and costs

\begin{tabular}{llll}
\hline Health state & HRG & Cost (£) & Notes \\
\hline Chronic hepatitis & G07 & 1406.00 & Non-elective cost (accounting for 89\% of activity) \\
Hepatocellular carcinoma & G07 & 1406.00 & \\
Compensated cirrhosis & G07 & 1406.00 & \\
Ascites & G07 & 1406.00 & \\
Refractory ascites & G07 & 1406.00 & \\
Variceal bleeding & F64 & 800.41 & Average of elective and non-elective costs \\
Hepatic encephalopathy & G07 & 1406.00 & \\
\hline
\end{tabular}




\begin{tabular}{ll}
$\begin{array}{l}\text { Table } 4 \text { Quality of life weights applied to health } \\
\text { states }\end{array}$ \\
\hline Health state & $\begin{array}{c}\text { Quality of life weight } \\
\text { (on scale 0-1) }\end{array}$ \\
\hline Seropositive for HCV & 0.95 \\
Mild chronic hepatitis & 0.98 \\
Moderate chronic hepatitis & 0.92 \\
Compensated cirrhosis & 0.82 \\
Diuretic sensitive ascites & 0.75 \\
Diuretic resistent ascites & 0.52 \\
Hepatic encephalopathy & 0.53 \\
Variceal haemorrhage & 0.55 \\
Hepatocellular carcinoma & 0.55 \\
\hline HCV, hepatitis C virus. &
\end{tabular}

monotherapy, our results suggest that changing to combination therapy is cost effective in most groups, with cost per QALY below $£ 5000$. The results do not appear to be sensitive to major changes in assumptions regarding key parameters although drug costs emerge as the most important source of variation in the sensitivity analyses.

A number of limitations in our study should be acknowledged. Cost estimates are inevitably imprecise, being based on reports from a small number of trusts or on reported costs for HRGs. In the absence of sound bottom up costings of the consequences of HCV disease, this is difficult to remedy although the sensitivity analysis demonstrates that the findings of our analysis are insensitive to 50\% upward and downward variation in cost assumptions. HRGs were used to estimate inpatient costs and there are likely to be variations in what has

\begin{tabular}{|c|c|c|c|c|c|c|}
\hline Strategy & QALY & $\begin{array}{l}\text { Lifetime } \\
\text { cost (£) }\end{array}$ & $\begin{array}{l}\text { Marginal } \\
\operatorname{cost}(£)\end{array}$ & $\begin{array}{l}\text { Marginal } \\
\text { effectiveness } \\
\text { (QALY) }\end{array}$ & $\begin{array}{l}\text { Marginal cost } \\
\text { effectiveness } \\
\text { (£/QALY) }\end{array}$ & $\begin{array}{l}\text { Discounted } \\
\text { marginal cost } \\
\text { effectiveness } \\
@ 6 \% \\
\text { (£/QALY) }\end{array}$ \\
\hline \multicolumn{7}{|c|}{ Combination therapy $v$ no treatment } \\
\hline No treatment & 22.8 & 13729 & & & & \\
\hline Combination therapy & 27.6 & 14456 & 523.47 & 4.82 & 151 & 3791 \\
\hline \multicolumn{7}{|c|}{ Combination therapy $v$ monotherapy } \\
\hline Monotherapy & 24.7 & 14363 & & & & \\
\hline Combination therapy & 27.6 & 14456 & 93.93 & 2.95 & 32 & 3485 \\
\hline
\end{tabular}

a more important determinant of cost effectiveness than assumptions about costs of treatment or disease progression.

\section{DISCUSSION}

Our results suggest that interferon and ribavirin are quite cost effective. Without considering the timing of costs and benefits, the additional cost of combination therapy is almost completely offset by future savings. Because the benefits are delayed, discounting is important. Although the appropriate rate is contentious, using a discount rate of $6 \%$ for both costs and benefits, we showed that combination therapy was likely to produce an additional QALY for less than $£ 3000$. This is considered by some as below a decision threshold for obtaining strong support from NHS commissioners. ${ }^{37}$ In some groups of patients combination therapy appears to be more cost effective, with discounted cost effectiveness below £1000 per QALY. Our results show that even in groups least likely to respond, the cost effectiveness of combination over monotherapy falls below $£ 10 \quad 000$. Compared with accepted been included in these costs. For example, inclusion of terlipressin or octreotide in the management of varices in HRG costs (which we believe is unlikely) would bias our results against therapy for HCV as these elements are costed separately. Our survey of hepatologists revealed a move towards nurse led clinics for the management of patients on combination therapy. This will reduce the outpatient management costs of treatment although such changes are very unlikely to be captured in standard NHS accounting practices, further emphasising the importance of better costing studies.

We have assumed that viral clearance is lifelong for almost all patients and that life expectancy is nearly normal. However, with reduction in HCV spread through blood transfusions, the proportion of the seroprevalent population made up of intravenous drug users is likely to increase. Reinfection of those treated because of recurrent injection drug use may be a significant problem, and resumed drug use would also reduce their life expectancy. These factors suggest that our

\begin{tabular}{|c|c|c|c|c|c|c|}
\hline \multirow[b]{2}{*}{ Subgroup } & \multicolumn{3}{|c|}{ Combination therapy $v$ no treatment } & \multicolumn{3}{|c|}{ Combination therapy $v$ monotherapy } \\
\hline & $\begin{array}{l}\text { Marginal } \\
\operatorname{cost}(£)\end{array}$ & $\begin{array}{l}\text { Marginal } \\
\text { effectiveness } \\
\text { (QALY) }\end{array}$ & $\begin{array}{l}\text { Marginal cost } \\
\text { effectiveness } \\
\text { (£/QALY) }\end{array}$ & $\begin{array}{l}\text { Marginal } \\
\operatorname{cost}^{\prime}(£)\end{array}$ & $\begin{array}{l}\text { Marginal } \\
\text { effectiveness } \\
\text { (QALY) }\end{array}$ & $\begin{array}{l}\text { Marginal cost } \\
\text { effectiveness } \\
\text { (£/QALY) }\end{array}$ \\
\hline Men & 4701 & 1.11 & 4247 & 2603 & 0.76 & 3429 \\
\hline Women & 4289 & 1.47 & 2913 & 2556 & 0.73 & 3514 \\
\hline Genotype 1 & 6330 & 0.69 & 9170 & 4327 & 0.50 & 8626 \\
\hline Genotype 2 or 3 & 2848 & 1.73 & 1646 & 861 & 0.99 & 872 \\
\hline Age 40 y or less & 4398 & 1.50 & 2942 & 2511 & 0.79 & 3197 \\
\hline Age $41-50 y$ & 4868 & 1.00 & 4855 & 2722 & 0.73 & 3705 \\
\hline Age over 50 y & 4873 & 0.76 & 6402 & 2901 & 0.58 & 5016 \\
\hline Viral load $>2$ million counts & 4796 & 1.12 & 4299 & 2772 & 0.75 & 3676 \\
\hline Viral load $\leqslant 2$ million counts & 4620 & 1.27 & 3627 & 2688 & 0.56 & 4792 \\
\hline Mild hepatitis & 5507 & 0.80 & 6925 & 3083 & 0.52 & 5900 \\
\hline Moderate hepatitis & 4161 & 1.44 & 2897 & 2356 & 0.86 & 2735 \\
\hline
\end{tabular}


Table 7 Results: sensitivity analyses

\begin{tabular}{|c|c|c|c|c|c|c|}
\hline \multirow[b]{2}{*}{ Sensitivity analysis } & \multicolumn{3}{|c|}{ Combination therapy $v$ no treatment } & \multicolumn{3}{|c|}{ Combination therapy $v$ monotherapy } \\
\hline & $\begin{array}{l}\text { Marginal } \\
\text { cost }(£)\end{array}$ & $\begin{array}{l}\text { Marginal } \\
\text { effectiveness } \\
\text { (QALY) }\end{array}$ & $\begin{array}{l}\text { Marginal cost } \\
\text { effectiveness } \\
\text { (£/QALY) }\end{array}$ & $\begin{array}{l}\text { Marginal } \\
\text { cost }(£)\end{array}$ & $\begin{array}{l}\text { Marginal } \\
\text { effectiveness } \\
\text { (QALY) }\end{array}$ & $\begin{array}{l}\text { Marginal cost } \\
\text { effectiveness } \\
\text { (£/QALY) }\end{array}$ \\
\hline Reduce cost of combination therapy by $50 \%$ & 1313 & 1.21 & 1084 & -683 & 0.74 & Dominated \\
\hline Increase cost of combination therapy by $50 \%$ & 7866 & 1.21 & 6497 & 5871 & 0.74 & 7887 \\
\hline Reduce cost of treating consequences of HCV infection by $50 \%$ & 5571 & 1.21 & 4602 & 3286 & 0.74 & 4415 \\
\hline Increase cost of treating consequences of HCV infection by $50 \%$ & 3607 & 1.21 & 2980 & 1902 & 0.74 & 2555 \\
\hline Reduce annual likelihood of progressive liver disease by $50 \%$ & 5385 & 0.71 & 7617 & 3072 & 0.44 & 7039 \\
\hline Increase annual likelihood of progressive liver disease by $50 \%$ & 3847 & 1.68 & 2286 & 2151 & 1.03 & 2081 \\
\hline
\end{tabular}

results may be optimistic for this population although it is impossible to predict to what extent.

The transplantation rates we have imputed are lower than those calculated for the USA and possibly lower than current UK practice. It is likely that improvements in transplant technology and organ availability with consequent reduction in the clinical threshold for transplantation could increase the value of avoiding this costly procedure through early treatment.

Our results are necessarily based on the results of clinical trials carried out to date. But exclusion criteria imply that these included only a small proportion of those who might now be considered for combination therapy in the UK. Our survey of hepatologists revealed considerable variation in the application of criteria for combination treatment, reflecting the genuine uncertainties of clinicians. A better understanding of this variation will be important to inform further pragmatic research into the value of combination therapy and to ensure equity of access to this potentially valuable treatment. While such variation and uncertainty exists, we consider it important that treatment should be confined to specialist centres, as recommended by the British Society of Gastroenterology and the European Society for the Study of the Liver.

\section{ACKNOWLEDGEMENTS}

We thank the staff of the following NHS trusts for their efforts in providing cost information: Hull Royal Infirmary; Greenwich Hospitals; Royal Devon and Exeter; University of Bristol Hospitals, Bristol; Freeman Road Hospital, Newcastle; Royal Free Hospital, London; Selly Oaks Hospital, Birmingham; and Heatherwood and Wexham Park Hospitals, Slough. We are particularly grateful to Dr David Carson of the costings unit at Ninewells Hospital, Dundee, for providing information on costs of investigations.

Hepatologists who took part in the survey of UK practice: Chris Tibbs, Graeme Alexander, David Mutimer, John Christie, Maggie Bassendine, Steve Ryder, Charles Milson, Mathew Cramp.

We also thank Sr Jo Guy, Sr Liz Burge, Dr Nick Sheron, and Prof John Iredale at Southampton General Hospital for providing survey data on symptom management and adverse event rates on treatment. We are grateful to the investigators and institutions participating in the International Hepatitis Interventional Therapy (IHIT) Group and Schering Plough for individual patient data from the clinical trials of combination therapy to allow subgroup analysis.

Sources of funding: Ken Stein was funded by Schering Plough for involvement in this study.

Contributions: Ken Stein helped to design the study. He was involved in ensuring the design of the decision analysis model reflected UK practice and collected UK based information to inform the analysis. He drafted the manuscript and is the corresponding author. William Rosenberg helped to design the study. He was involved in the design of the decision analysis model to reflect UK practice. He contributed to the drafting of the manuscript. John Wong helped to design the study. He designed the basic decision analysis model and amended this to reflect UK practice. He contributed to the drafting of the manuscript.

\section{Authors' affiliations}

K Stein, University of Exeter, Exeter, UK

W Rosenberg, University of Southampton, Southampton, UK

J Wong, Division of Clinical Decision Making, New England Medical

Centre, Tufts University School of Medicine, Boston, USA

\section{REFERENCES}

1 Rosenberg WM. Screening and shouting about HCV. Gut 2000:47: 165-6.

2 McLindon J, Paver W, Babbs C, et al. Hepatitis C related chronic liver disease among asymptomatic blood donors in the North West of England. J Infect 1995;30:253-9.

3 Sallie R, King R, Silva E, et al. Community prevalence of hepatitis $C$ viraemia: a polymerase chain reaction study. J Med Virol 1994;43:111-14.

4 Ward C, Tudor-Williams G, Cotzias T, et al. Prevalence of hepatitis C among pregnant women attending an inner London obstetric department: uptake and acceptability of named antenatal testing. Gut 2000;47:277-80.

5 Waller T, Holmes R. Hepatitis C: scale and impact in Britain. The sleeping giant wakes. Druglink 1995;8-11.

6 Seeff LB. Natural history of hepatitis C. Hepatology 1997;26:21S-8S.

7 Pagliaro L, Peri V, Linea C, et al. Natural history of chronic hepatitis C. Ital J Gastroenterol Hepatol 1999;31:28-44.

8 Poynard T, Bedossa P, Opolon P. Natural history of fibrosis progression in patients with chronic hepatitis C. Lancet 1998;349:825-32.

9 Detre KM, Belle SH, Lombardero M. Liver transplantation for chronic viral hepatitis. Viral Hepat Rev 1996;2:219-28.

10 Poynard T, Marcellin P, Lee SS, et al. Randomised trial of interferon alpha $2 b$ plus ribavirin for 48 weeks or for 24 weeks versus interferon alpha2b plus placebo for 48 weeks for treatment of chronic infection with hepatitis $\mathrm{C}$ virus. International Hepatitis Interventional Therapy Group (IHIT). Lancet 1998;352:1426-32

11 McHutchison JG, Gordon SC, Schiff ER, et al. Interferon alfa-2b alone or in combination with ribavirin as initial treatment for chronic hepatitis C. Hepatitis Interventional Therapy Group. N Engl J Med 1998;339: 1485-92.

12 Weinstein MC, Stason WB. Foundations of cost effetiveness analysis for health and medical practice. N Engl J Med 1977;296:716-21.

13 Bennett WG, Inove Y, Beck JR, et al. Estimates of the cost-effectiveness of a single course of interferon-alpha $2 \mathrm{~b}$ in patients with histologically mild chronic hepatitis C. Ann Intern Med 1997; 127:855-65.

14 Fattovich G, Giustina G, Degos F, et al. Morbidity and mortality in compensated cirrhosis type C: a retrospective follow-up study of 384 patients. Gastroenterology 1997;1 12:463-72.

15 Seeff LB, Buskell-Bales Z, Wright EC, et al. Long-term mortality after transfusion-associated non-A, non-B hepatitis. The National Heart, Lung, and Blood Institute Study Group. N Engl J Med 1992;327:1906-1 1.

16 Martinot-Peignoux M, Marcellin P, Pouteau M, et al. Pretreatment serum hepatitis $C$ virus RNA levels and hepatitis $C$ virus genotype are the main and independent prognostic factors of sustained response to interferon alfa therapy in chronic hepatitis C. Hepatology 1995;22:1050-6.

17 Marcellin P, Pouteau M, Benhamou JP. Hepatitis $C$ virus infection, alpha interferon therapy and thyroid dysfunction. J Hepatol 1995;22:364-9.

18 Mahaney K, Tedeschi V, Maertens G, et al. Genotypic analysis of hepatitis $C$ virus in American patients. Hepatology 1994;20:1405-11

19 Pagliaro L, Craxi A, Cammaa C, et al. Interferon-alpha for chronic hepatitis $C$ : an analysis of pretreatment clinical predictors of response. Hepatology 1994;19:820-8.

20 Lau JY, Davis GL, Kniffen J, et al. Significance of serum hepatitis C virus RNA levels in chronic hepatitis C. Lancet 1993;341:1501-4

21 Perez R, Pravia R, Linares A, et al. Response related factors in recombinant interferon alfa-2b treatment of chronic hepatitis $C$. Gut 1993;34:S139-40.

22 Battezzati PM, Podda M, Bruno S, et al. Factors predicting early response to treatment with recombinant interferon alpha-2a in chronic 
non-A, non-B hepatitis. Preliminary report of a long-term trial. Ital J Gastroenterol 1992;24:481-4.

23 Takahashi M, Yamada G, Miyamoto R, et al. Natural course of chronic hepatitis C. Am J Gastroenterol 1993;88:240-3.

24 Tremolada F, Casarin C, Alberti A, et al. Long-term follow-up of non-A, non-B (type C) post-transfusion hepatitis. J Hepatol 1992;16:273-81.

25 Mattsson L. Chronic non-A, non-B hepatitis, PhD thesis. Stockholm: Karolinska Institute, 1989.

26 The Veterans Affairs Cooperative Variceal Sclerotherapy Group Sclerotherapy for male alcoholic cirrhotic patients who have bled from esophageal varices: results of a randomized, multicenter clinical trial. Hepatology 1994;20:618-25.

27 Salerno F, Borroni G, Moser P, et al. Survival and prognostic factors of cirrhotic patients with ascites: a study of 134 outpatients. Am J Gastroenterol 1993:88:514-19.

28 Christensen E, Krintel JJ, Hansen SM, et al. Prognosis after the first episode of gastrointestinal bleeding or coma in cirrhosis. Survival and prognostic factors. Scand J Gastroenterol 1989;24:999-1006.

29 Tsukuma H, Hiyama T, Tanaka S, et al. Risk factors for hepatocellular carcinoma among patients with chronic liver disease. N Engl J Med 1993;328:1797-801.
30 Colombo M, de Franchis R, Del Ninno E, et al. Hepatocellular carcinoma in Italian patients with cirrhosis. N Engl J Med 1991;325:675-80.

31 Wong JB, Bennett WG, Koff RS, et al. Pretreatment evaluation of chronic hepatitis C: risks, benefits, and costs. JAMA 1998;280:2088-93.

32 Sobesky R, Mathurin P, Charlotte F, et al. Modeling the impact of interferon alfa treatment on liver fibrosis progression in chronic hepatitis C: a dynamic view. The Multivirc Group. Gastroenterology $1999 ; 116: 378-86$.

33 British National Formulary. London: British Medical Association, Royal Pharmaceutical Society of Great Britain, 1999.

34 National Specialist Commissioning Advisory Group (NSCAG). Annual Report of the National Specialist Commissioning Advisory Group (1997/8). London: NHS Executive, 1999.

35 NHS Executive. Financial Matters. Leeds: NHS Executive, 1999.

36 NHS Executive. 1998/9 Extra-Contractual Referral Tariffs. Bristol: NHS Executive, South and West, 1998.

37 Best L, Stevens A, Colin-Jones D. Rapid and responsive health technology assessment: the development and evaluation process in the South and West region of England. J Clin Effect 1997;2:51-6.

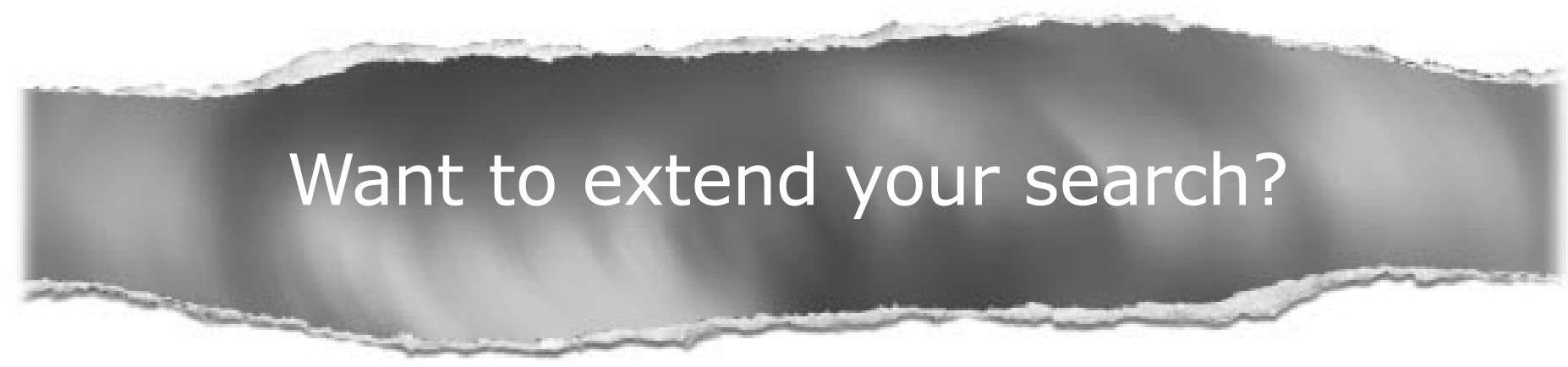

Cross journal searching

If you can't find what you are looking for in Gut you can extend your search across many of the more than 200 journals available for selection. You can restrict your search to specific subject areas (eg, clinical medicine, basic research), or select specific journals, or search all available titles.

www.gutjnl.com 